\section{Estratégias de mudança na atenção básica: avaliação da implantação piloto do Projeto Homens Jovens e Saúde no Rio de Janeiro, Brasil}

\author{
Strategies for changes in primary health care: \\ evaluating the pilot implementation of the Project \\ on Young Men's Health in Rio de Janeiro, Brazil
}

Ivani Bursztyn 1

\section{Introdução}

To improve young men's adherence to a teenage health care program, a project was developed and implemented with a pilot phase in primary health centers in the city of Rio de Janeiro, Brazil. This article presents the results of an evaluation performed at the end of the first year, aimed at identifying characteristics in the health care services that play a strategic role for change, as well as those that contribute to resistance. The methodology was based on participatory planning techniques and rapid assessment procedures (RAP). Considering the principles of the program's practices, a matrix was developed with five categories: implementation of the project's activities, interdisciplinary health team, health care organization, inter-sector cooperation, and user participation. Self-assessment workshops were held with the local teams. Despite good awareness among the health professionals, the project's results varied between health centers. Over-centralization and lack of flexibility appear to be related to lower capacity to incorporate new practices. Meanwhile, the health centers where specific strategies were observed also showed more successful results.

Adolescent Health; Men's Health; Primary Health Care
Nos últimos anos vem se consolidando o entendimento de que a saúde do adolescente constitui uma questão específica, destacada da pediatria e da clínica. É neste período que se molda, em grande parte, a maneira como os jovens viverão sua vida adulta, demandando atenção, não apenas no que se refere à saúde sexual e reprodutiva, mas, também, quanto aos aspectos de sua vida produtiva, social e econômica 1 .

O desenvolvimento de iniciativas neste sentido tem demandado um grande esforço tanto na esfera político-administrativa quanto no campo da pesquisa, propiciando a parceria entre instituições públicas de planejamento e execução de políticas, instituições acadêmicas e organizações não governamentais. O Programa de Atenção Integral à Saúde do Adolescente começou a ser implantado no Rio de Janeiro, Brasil, em 1986, antes mesmo da promulgação do Programa de Saúde do Adolescente (PROSAD) ${ }^{2}$, o que veio a ocorrer em 1989 3. Desde então têm sido priorizadas as ações referentes à sexualidade, gravidez e doenças sexualmente transmissíveis, em consonância com as diretrizes que vieram a ser preconizadas pelo PROSAD 4 . A grande ênfase dada à promoção do uso de contraceptivos e no acompanhamento pré-natal das adolescentes grávidas gerou uma polaridade de gênero, deixando de se enfocar as necessidades próprias do homem jovem. Visando preencher esta lacuna a 
Secretaria Municipal de Saúde do Rio de Janeiro (SMS-RJ) procurou alternativas para incrementar a adesão deste segmento aos serviços de atenção básica. Um projeto foi desenvolvido e implantado por uma organização não-governamental em cooperação com a SMS-RJ e uma universidade pública, com suporte da Organização Pan-Americana da Saúde (OPAS) / Organização Mundial da Saúde (OMS): Projeto Homens Jovens e Saúde 5. O projeto consistiu em um levantamento de informações junto ao grupo-alvo e provedores de serviços, organização de seminário e capacitação dos profissionais, envolvimento do grupo-alvo na produção de material educativo e de divulgação dos serviços, além do monitoramento das atividades dos serviços no período de implementação. Enfatizou-se a consolidação de parcerias entre as unidades e demais atores sociais envolvidos em iniciativas, projetos e formulação de políticas públicas voltadas para os direitos dos adolescentes e dos jovens. A identificação de necessidades próprias a este grupo estava entre os objetivos iniciais, evidenciando o pouco conhecimento consolidado neste campo.

No âmbito dos serviços municipais, a implantação do projeto piloto se deu em duas áreas da cidade, ambas com baixo desempenho nos indicadores sócio-econômicos e com alto percentual de população jovem. Foram incluídas cinco unidades de saúde com os seguintes perfis:

- Unidade 1: centro de saúde situado em uma região com extrema escassez de recursos de saúde, especialmente aqueles de média e alta complexidade. Neste contexto, esta unidade assume a posição de principal referência para uma rede de postos de saúde de menor porte que funcionam, em sua maioria, precariamente, devido à dificuldade de fixação dos profissionais médicos e enfermeiros;

- Unidade 2: posto de saúde, apesar de estar na mesma região que a Unidade 1 , com baixa concentração de serviços de saúde, situa-se em um bairro com razoável infra-estrutura urbana. Atua em uma área de abrangência bem delimitada, estabelecendo vínculo forte com a população atendida;

- Unidade 3: centro de saúde situado no interior de um complexo de favelas e integrado em uma região com alta concentração de serviços de saúde, inclusive de média e alta complexidade. Neste contexto a unidade funciona com área de abrangência bem delimitada e vínculo forte com a população atendida, semelhante à Unidade 2;

- Unidade 4 e Unidade 5: postos de saúde que foram transformados em módulos do Programa Saúde da Família (PSF), situadas no mesmo complexo de favelas onde se encontra a Unidade 3. Aqui o programa de saúde do adolescente criou uma estrutura mais dinâmica e ágil visando melhor adequação de respostas do programa, o Adolescentro. Composto por equipe interdisciplinar e agentes de saúde recrutados entre os jovens da própria comunidade, o Adolescentro esteve encarregado do planejamento e implementação das ações voltadas aos adolescentes, incluindo o Projeto Homens Jovens e Saúde mobilizando parcerias em setores externos à saúde, como esporte, cultura, arte e lazer.

Neste artigo apresentamos uma avaliação das mudanças incorporadas na rotina das unidades em que o projeto foi implementado de forma piloto. A prática da avaliação em saúde tem se desenvolvido bastante, tanto pela premência de basearem-se as decisões em critérios científicos quanto pelas possibilidades oferecidas pela crescente tecnologia de informação. No entanto, os esforços para estabelecer uma cultura da avaliação não têm produzido o desejado impacto na crise que enfrentam os sistemas de saúde. Contandriopoulos 6 postula que o grau de influência dos resultados da avaliação sobre os processos decisórios depende de sua credibilidade, fundamentação teórica e pertinência. Estudos de avaliação podem ser classificados em três tipos 7: (i) investigação avaliativa, visa o conhecimento, foca o impacto e usa os resultados como demonstração; (ii) avaliação para a decisão, visa a tomada de decisão, foca a compreensão dos processos e outcomes e utiliza os resultados como informação; (iii) avaliação para a gestão, visa o aprimoramento, foca a compreensão dos processos e utiliza os resultados como instrumento para a gestão.

O presente estudo tem características de avaliação para gestão, uma vez que visa compreender a relação entre a dinâmica do serviço e a mudança nas práticas dos profissionais. Adotou-se uma metodologia participativa, consistindo em estratégia que, ao mesmo tempo em que considera as opiniões e perspectivas dos envolvidos, promove a rápida assimilação e utilização dos resultados 8 . O levantamento de campo, realizado com a participação das equipes, se deu um ano após o início do projeto e teve como objetivo, a partir dos desafios do PROSAD e do Projeto Homens Jovens e Saúde, identificar os fatores que facilitam ou opõem obstáculos à mudança e ao efetivo desenvolvimento da proposta.

\section{Os desafios do PROSAD}

Os desafios enfrentados pelo PROSAD processam-se em diferentes contextos e arenas, e formam a base dos critérios utilizados para a avaliação do Projeto Homens Jovens e Saúde. Na arena 
das políticas de saúde, nem sempre é possível assegurar-se prioridade para a atenção aos adolescentes, uma vez que sua participação no quadro de morbi-mortalidade e sua busca por atenção médica são menores do que a de outros grupos, tais como o de crianças, mulheres e idosos. A priorização dos adolescentes depende da adoção de um enfoque que privilegie a promoção da saúde e as atividades voltadas para o coletivo. Trata-se, assim, de resguardar-se o enfoque de saúde integral, com ênfase na vigilância do crescimento e desenvolvimento contrapondo-se à intervenção dirigida aos problemas, tais como DST/AIDS ou uso de drogas, gravidez etc. 1,9,10,11.

No contexto da gestão dos serviços o grande desafio que se coloca é o de adequar-se para possibilitar a captação e adesão dos adolescentes, contemplando singularidades relativas a gênero, condição sócio-econômica, vínculos familiares, domicílio, incapacidades, escolaridade, trabalho e faixa etária atendida. Especial ênfase deve ser dada à captação de adolescentes de maior vulnerabilidade. Adicionalmente podemos citar a necessidade de fortalecer a integração entre os profissionais dos diferentes programas e setores da unidade, fomentar a educação continuada, implementar a avaliação permanente que fortaleça os profissionais, valorize a criatividade e promova o diálogo entre a equipe e os adolescentes $1,9,11,12$.

No contexto da integralidade da atenção é necessário promover oportunidades de acesso a atividades profissionalizantes, esportivas, artísticas e de lazer; contemplar de forma abrangente a família e a comunidade; assegurar acesso aos profissionais de saúde adequados, sempre que necessário 1,10,11.

No contexto da promoção da cidadania e inclusão social cabe estimular a participação dos adolescentes nos serviços e nas atividades de promoção de saúde na comunidade, além de qualificar o diálogo com os adolescentes, visto que muitas vezes os serviços ignoram as reais necessidades e desejos da clientela com a qual trabalha $1,10,11,13$.

\section{Metodologia}

O estudo dos efeitos produzidos por uma intervenção tem utilidade para a tomada de decisão quanto a adotá-la ou não, mas não fornece elementos explicativos para os possíveis sucessos ou fracassos. Por outro lado, a avaliação de implantação de uma intervenção envolve o estudo dos determinantes e da variação na implantação sobre os efeitos esperados, possibilitando a compreensão do processo ${ }^{14}$. A análise de implan- tação pode se dar pelo estudo da influência de elementos contextuais sobre o grau de implantação da intervenção; da influência das variações do grau de implantação sobre os resultados da intervenção; dos efeitos da interação entre contexto e intervenção sobre os resultados. Elementos da realidade imediata em que um projeto ou intervenção é implantado podem dificultar o seu pleno desenvolvimento, fazendo com que a implantação se dê de forma parcial. A não efetividade dos resultados pode estar relacionada com a insipiência na implantação da proposta. Por fim, entre a realidade imediata e o projeto/intervenção implantado pode haver sinergias ou antagonismos que se refletem nos resultados, seja potencializando-os ou opondo obstáculos a sua efetividade 14 .

Neste estudo realizou-se a análise da implantação do projeto de atenção ao homem jovem com vistas a identificar os fatores que facilitam ou opõem obstáculos à mudança e ao seu efetivo desenvolvimento.

Metodologias avaliativas devem respeitar a pluralidade de contextos das ações programáticas, assim como a complexidade da medida de resultados 15 . Os procedimentos metodológicos pautaram-se em um modelo que vem sendo desenvolvido desde 1997 em cooperação com programa de saúde do adolescente do Município do Rio de Janeiro e o Fundo das Nações Unidas para a Infância (UNICEF) 16,17. Trata-se de uma metodologia participativa adotando-se uma abordagem de RAP (rapid assessment procedures) 18,19,20. Esta abordagem vem sendo implementada nos últimos trinta anos, em diferentes campos, envolvendo diversas disciplinas, tais como: antropologia, economia, epidemiologia, avaliação de políticas e programas sociais. De acordo com Macintyre 21, o emprego conjunto de técnicas diferentes propicia uma fertilização cruzada (crossfertilization) de idéias entre as disciplinas.

A metodologia participativa empregada envolve quatro passos: (1) construção da matriz de análise, (2) realização da oficina de auto-avaliação, (3) elaboração da síntese dos resultados na matriz dos resultados e pontuação por meio de consenso no grupo, e (4) transposição das notas para o diagrama da teia.

\section{Passo 1: construção da matriz de análise}

A construção da matriz se fez a partir dos postulados do programa e do projeto a ser avaliado. A racionalidade da ação programática 17,22 é, aqui, expressa através dos cinco eixos: (i) implantação das ações do PROSAD, (ii) equipe interdisciplinar de saúde, (iii) organização da assistência, (iv) cooperação intersetorial e (v) participação do usuá- 
rio. A cada eixo corresponde um conjunto de critérios instituídos a partir dos objetivos e desafios do PROSAD e da experiência do programa, tanto no serviço quanto na gerência central. A matriz de análise foi utilizada como roteiro para suscitar a reflexão e discussão entre os participantes das oficinas de avaliação, mas não como um questionário a ser respondido em grupo (Tabela 1).

Passo 2: realização de oficinas

de auto-avaliação

Foram realizadas oficinas com as equipes das Unidades 1, 2, 3 e com a equipe do Adolescentro (responsável pelo projeto nas unidades 4 e 5). Foram convidados profissionais direta e indiretamente vinculados ao atendimento ao adolescente, inclusive os da recepção e porta de entrada. Todas as oficinas foram marcadas com antecedência e respeitando as prioridades locais, com vistas a assegurar o máximo de participação. A duração da oficina variou de 75 a 120 minutos, de acordo com o número de participantes. Na Unidade 1 a participação na oficina foi de apenas dois profissionais (assistente social e enfermeira), na Unidade 2 participaram quatro profissionais (médico, enfermeiros e assistente social), na Unidade 3 participaram seis profissionais (médicos, enfermeiros e psicólogo) e no Adolescentro participaram 11 integrantes da equipe (médicos, dentista, enfermeiro, assistente social, psicólogo e agentes comunitários de saúde). O menor ou maior número de profissionais participando na oficina está de acordo com o grau de desenvolvimento do projeto em cada unidade, como se verá, mais adiante, nos resultados.

\section{Passos 3: pontuação do desempenho pela equipe}

Ao final de cada oficina obteve-se como produto o resumo da discussão, empregando-se a técnica de VIPP (visualization in participatory planning) 8,20. A auto-avaliação é finalizada com um consenso negociado pelo grupo que identifica os principais pontos fracos e fortes do desempenho do programa na unidade, atribuindo-se notas em uma escala de 1 a 5 para cada eixo, em que 1 corresponde ao desempenho mais fraco e 5 ao melhor desempenho.

\section{Passo 4: visualização gráfica da avaliação}

As notas atribuídas a partir do consenso negociado são representadas em um gráfico radial (diagrama da teia) 20. Desta forma obtém-se a rápida visualização e apreensão dos resultados, podendo-se identificar os pontos fracos e fortes do serviço, assim como sua interação e possíveis estratégias para melhorar o desempenho.

Por basear-se na auto-avaliação realizada por meio de processo participativo, os resultados poderão estar influenciados por subjetividades diversas. É necessário que o moderador aponte os vieses de cada caso com vistas a uma análise comparativa. Por outro lado, a opção justifica-se, uma vez que este processo potencializa a apropriação dos resultados pela equipe, contribuindo para o seu fortalecimento (empowerment), e aumentando as chances de influenciar na tomada de decisão 18 .

\section{Resultados}

Apresentam-se a seguir os resultados referentes a cada oficina (Figuras 1, 2, 3 e 4) e a análise comparativa a partir da auto-avaliação do desempenho em cada eixo.

\section{Implantação das ações do programa}

Neste eixo as notas auto-atribuídas variaram de 3 a 4. A implementação do Projeto Homens Jovens e Saúde nas unidades contribuiu para reforçar a sensibilização da equipe, embora a repercussão no atendimento e nas rotinas do programa esteja ainda aquém do desejado: "Ainda não se percebe um aumento da presença do homem jovem na unidade de saúde que possa ser atribuída ao projeto, mas percebe-se que a equipe está mais sensibilizada para este segmento. A presença do homem jovem já foi maior no programa do adolescente. Porém, pela necessidade de se priorizar as moças (pré-natal e contracepção) as ações acabaram por se tornar mais dirigidas a este grupo, afastando os rapazes e outras moças que, por não estarem ainda com este tipo de preocupação, deixaram de se identificar com o programa" (Unidade 3).

É possível que a visão crítica da equipe em relação a este eixo se deva exatamente à expectativa gerada pela recente sensibilização para o problema. Ainda que tenha havido transferência de profissionais treinados para outras unidades, este não parece ser o principal obstáculo a mudanças, uma vez que existe uma considerável "contaminação" do restante da equipe com a consciência e sensibilização promovida pelo treinamento: "Hoje há uma maior consciência no conjunto dos profissionais que passaram a encaminhar os adolescentes para a assistente social [...] e a médica [...] identificadas como as pessoas chaves do programa" (Unidade 2).

As melhores avaliações corresponderam à Unidade 2, onde o PROSAD já possuía uma base mais sólida e equipe consolidada, e no Ado- 
Matriz para avaliação do projeto.

\begin{tabular}{|c|c|}
\hline Eixos de análise & Critérios \\
\hline Implantação das ações do & Que ações estão implantadas? \\
\hline \multirow[t]{8}{*}{ programa } & Há priorização do atendimento ao adolescente? Como é feita? \\
\hline & Há um fluxo dentro da unidade que facilite a captação? As atividades voltadas para adolescentes são divulgadas \\
\hline & internamente? Como é feita a captação do homem jovem? \\
\hline & Como funciona a captação na porta de entrada (balcão)? \\
\hline & Como a atenção ao adolescente se articula com outras ações tais como saúde escolar, DST, odontologia, etc.? \\
\hline & Quais são os grupos prioritários para o programa? Destes, quais estão sendo adequadamente atendidos? \\
\hline & O treinamento proporcionado pelo projeto contribuiu para aumentar a presença do homem jovem nas atividades \\
\hline & da unidade? \\
\hline Equipe interdisciplinar & Há diversidade de profissionais envolvidos? \\
\hline \multirow[t]{6}{*}{ de saúde } & Todos participam nas decisões? Há intercâmbio entre as diferentes categorias profissionais? \\
\hline & Com que freqüência a equipe se reúne para discutir e avaliar/programar o trabalho? Que informações utiliza? \\
\hline & Quantos profissionais envolvidos tiveram algum treinamento específico? Continuam na unidade? Qual o critério de \\
\hline & indicação para treinamentos? \\
\hline & Eles aplicam estes treinamentos no dia-a-dia? Há a preocupação de "socializar" os treinamentos? \\
\hline & A implantação do projeto contribuiu para modificar a dinâmica da equipe? \\
\hline \multirow[t]{8}{*}{$\begin{array}{l}\text { Organização da assistência } \\
\text { (estratégias locais) }\end{array}$} & $\begin{array}{l}\text { O que é exigido para que o adolescente seja atendido (documentos, presença de responsável etc.)? Quais as } \\
\text { estratégias desenvolvidas especificamente para as necessidades dos homens jovens? }\end{array}$ \\
\hline & O que é feito para facilitar a relação com o adolescente? Como é o equilíbrio entre atendimento de grupo e \\
\hline & individual? Há utilização de atividades lúdicas e esportivas articuladas com práticas educativas e de promoção? \\
\hline & O projeto melhorou a capacidade da equipe para lidar com questões tais como: \\
\hline & confidencialidade, flexibilidade de horário e outros, prescrição de contraceptivos sem a presença de responsáveis, \\
\hline & maus tratos, drogadição, homossexualidade, etnia, violência, tráfico, profissionalização, escolaridade e saúde entre \\
\hline & os que trabalham. \\
\hline & Como se trabalha a família? \\
\hline \multirow[t]{5}{*}{ Cooperação intersetorial } & Com que escolas e/ou outras organizações estabelece parcerias? \\
\hline & As parcerias estão contribuindo para aumentar a cobertura dos grupos de maior risco? \\
\hline & As parcerias contribuem para facilitar o acesso do adolescente ao serviço? \\
\hline & Há possibilidades de encaminhamento dos adolescentes a outros serviços (esporte, profissionalização etc.)? \\
\hline & A implantação do projeto estimulou novas parcerias? \\
\hline \multirow[t]{5}{*}{ Participação do adolescente } & Os adolescentes opinam na organização das atividades, escolha de temas etc.? \\
\hline & Os adolescentes são incentivados a avaliar o serviço? \\
\hline & Os adolescentes são incentivados a divulgar o programa? \\
\hline & Há parceria da unidade com grupos organizados de adolescentes? \\
\hline & O projeto contribuiu para melhorar a participação do jovem? Como? \\
\hline
\end{tabular}

lescentro que, como já referido anteriormente, é uma estrutura com muita flexibilidade para se articular internamente e para estabelecer as parcerias necessárias para o alcance de objetivos colocados.

“...Aos sábados são promovidas diversas atividades: atendimentos e grupos de gestantes, $m u$ lheres, homens, planejamento familiar, esporte, dança, teatro" (Adolescentro).

\section{Equipe interdisciplinar}

Neste eixo as notas auto-atribuídas variaram de 3 a 5 . De fato o padrão da equipe parece ser um diferencial para a qualidade do trabalho. Em um extremo encontra-se a Unidade 1, onde não há uma equipe própria do PROSAD, consistindo este de atividades educativas pontuais a cargo da assistente social: "As enfermeiras são plantonistas e não criam vínculo com os programas. A assistente social procura estabelecer cooperação 


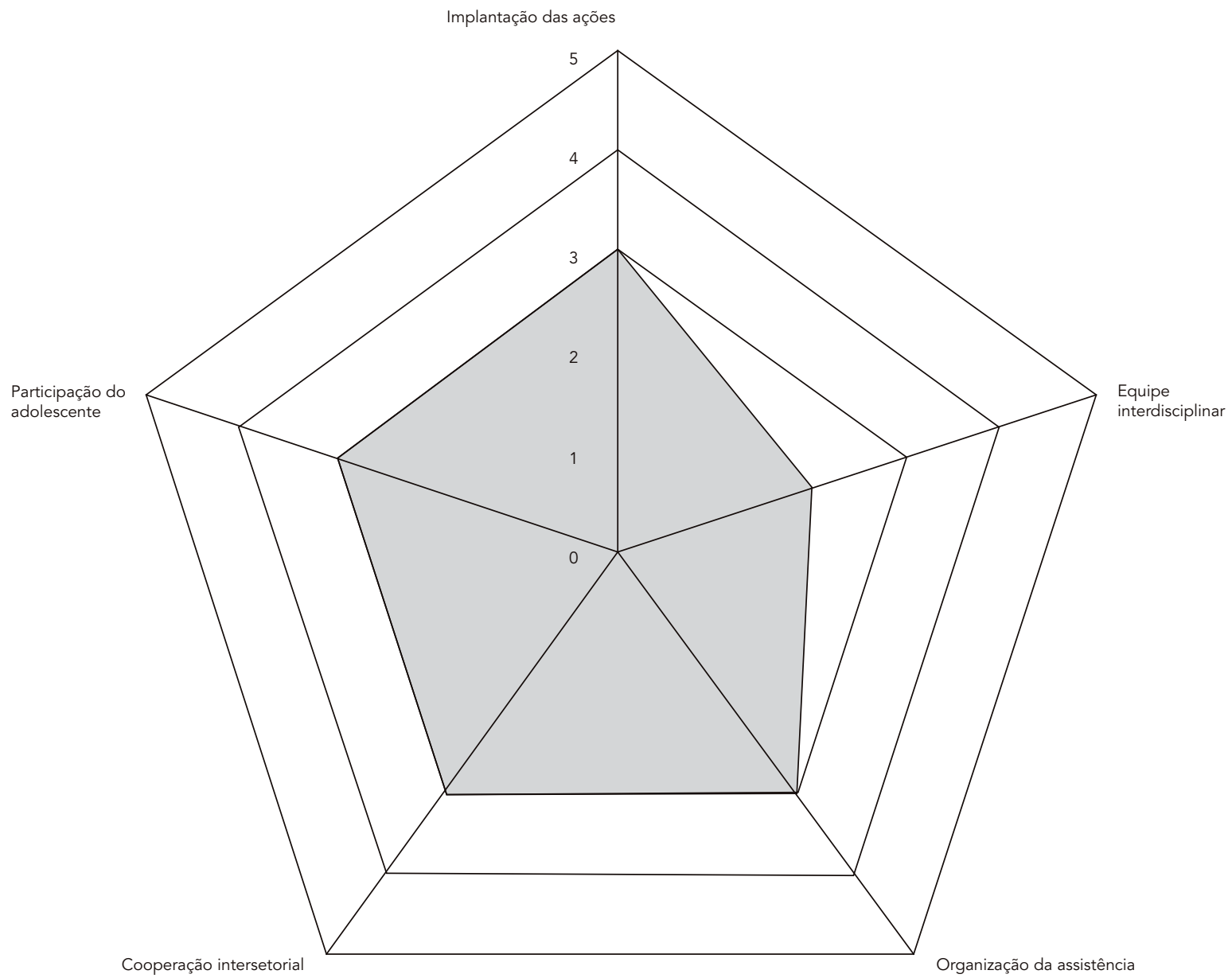

convidando os demais profissionais a participar dos grupos" (Unidade 1).

Ainda que ela procure se cercar da "consultoria” dos demais colegas, a abordagem integral do programa fica comprometida pela deficiência de número e diversidade dos profissionais efetivamente envolvidos na equipe e ações do programa. No outro extremo encontra-se o Adolescentro, cuja proposta assume com clareza os objetivos de promoção vinculada à abordagem interdisciplinar e intersetorial.

"Há reuniões específicas de monitores, promotores e técnicos, além de reuniões gerais. O projeto homem jovem sensibilizou e hoje há maior presença de rapazes entre os promotores" (Adolescentro).
A elaboração de estratégias de ação e desenvolvimento, e a avaliação dos projetos envolvem toda a equipe: desde os agentes de saúde (promotores e monitores), que são jovens recrutados na comunidade, até os técnicos e coordenadores. Além da troca constante nos espaços informais, que caracteriza uma equipe com alto grau de cooperação, existem vários momentos formais de reunião de equipe em vários níveis, próprios de um conceito de aprendizado permanente e treinamento continuado.

Nas Unidades 2 e 3 as equipes são estáveis e fortalecidas por vínculos informais e espírito de cooperação. A cobrança de produtividade centrada em quantidade de procedimentos e não na avaliação de resultados, aliada à desproporção 


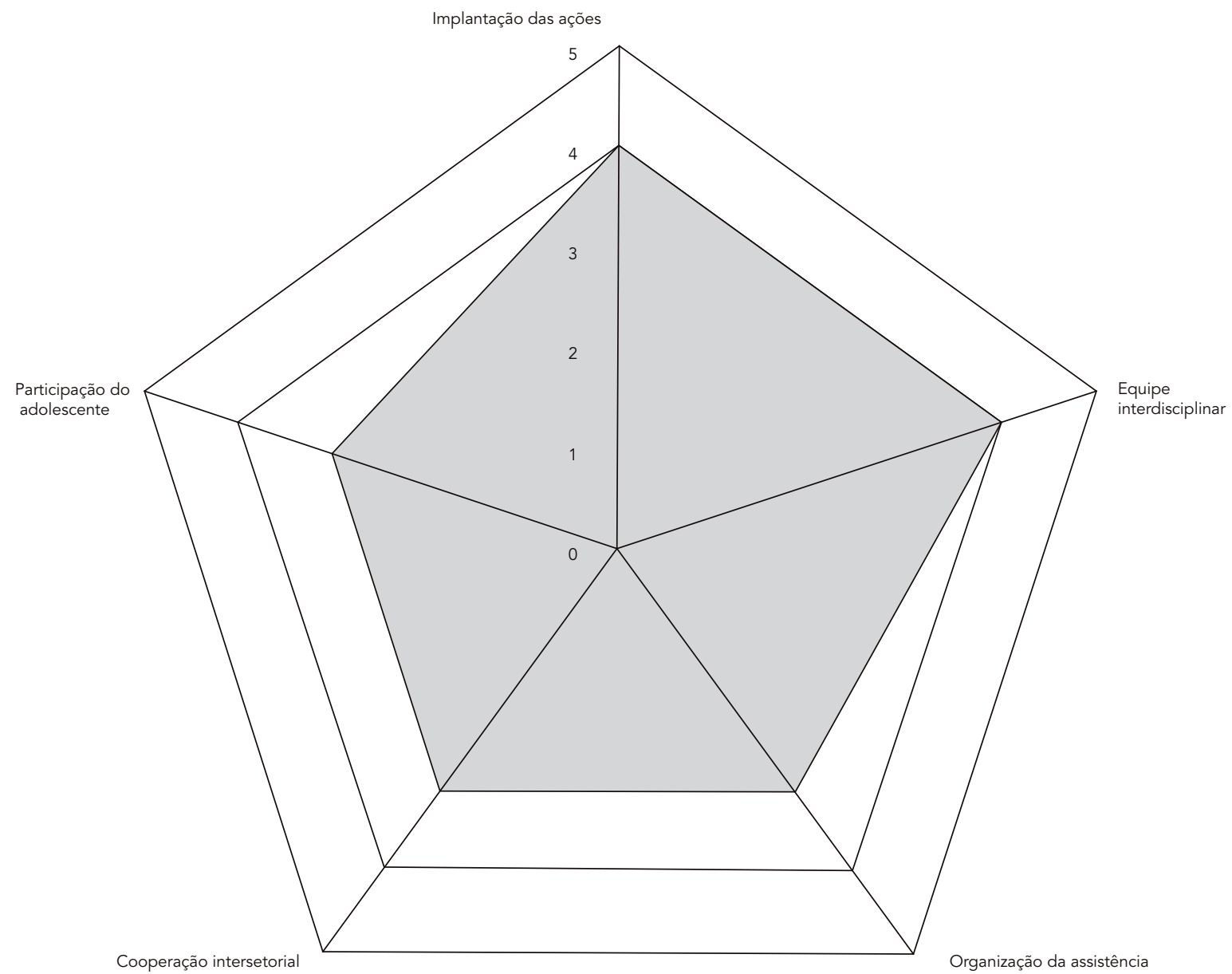

oferta/demanda, gera um modelo de trabalho em que reuniões e avaliações passam a ser tratadas como atividades a serem realizadas de acordo com o tempo (in)disponível: "Há diversidade disciplinar nos profissionais envolvidos, porém, há pouca oportunidade formal (reuniões de equipe) de troca de experiências apesar de haver um clima colaborativo de trabalho" (Unidade 3).

Desta forma a nota (4) que as equipes das Unidades 2 e 3 se atribuem reflete uma consciência do esforço próprio dos profissionais, apesar do reconhecimento das limitações e fragilidades institucionais.

\section{Organização da assistência}

Neste eixo as notas auto-atribuídas variaram entre 3 e 4 . Nas unidades de saúde já há uma tradição do PROSAD em não criar entraves burocráticos à entrada do adolescente, por tratar-se de um grupo de comportamento instável, próprio da idade. No entanto, devido à falta de recursos, ainda não foi possível implementar a estratégia proposta pelas equipes para facilitação do trabalho com o homem jovem, que seria a disponibilização de profissional do sexo masculino. A exceção é o Adolescentro, que devido à sua estrutura flexível pode incorporar um maior número de promotores/monitores do sexo masculino para fazer frente a esta nova demanda. As estratégias 


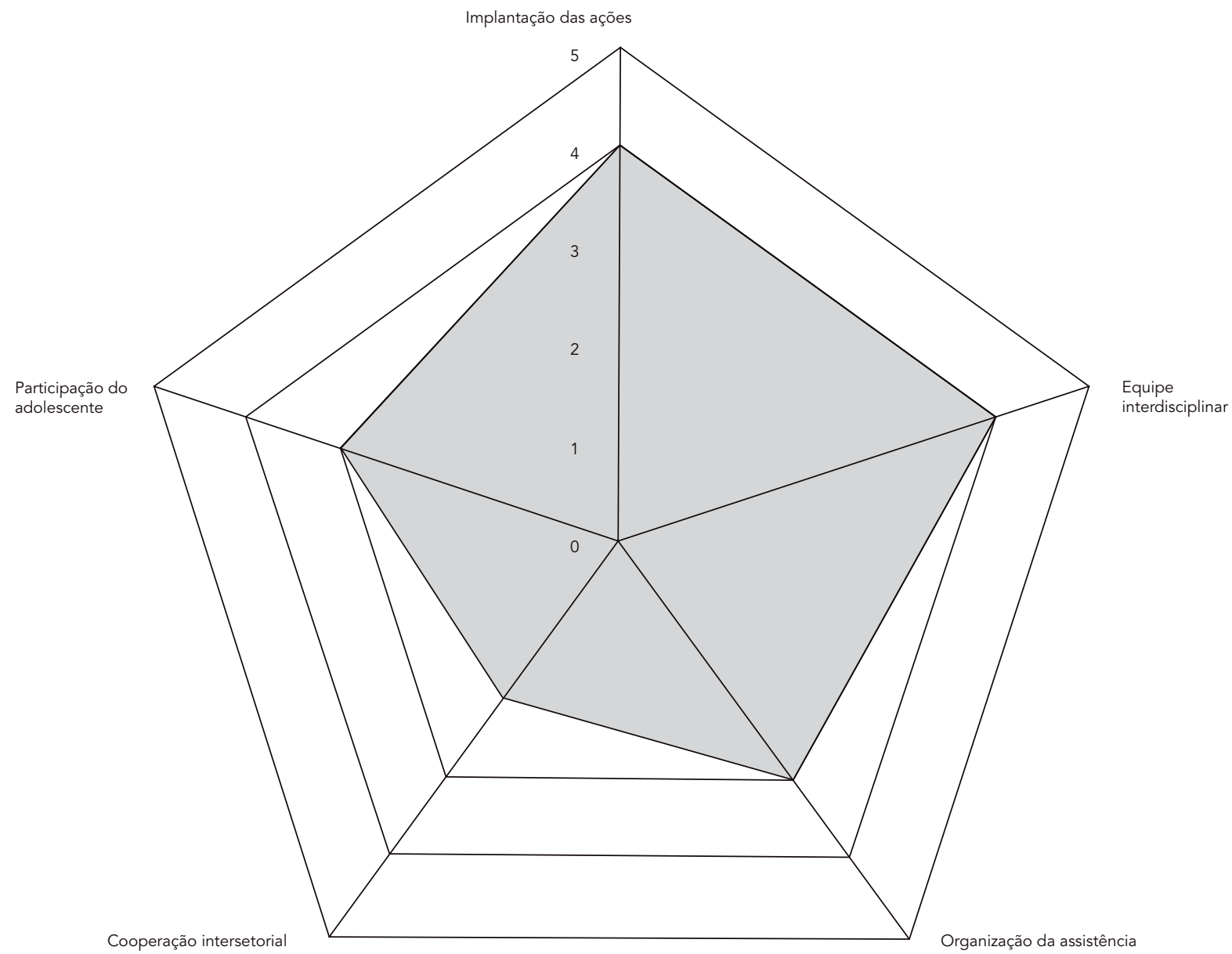

também são facilitadas pela abordagem intersetorial (saúde, esporte, cultura, arte etc.), pela ênfase no trabalho do jovem para o jovem e pela sistemática de avaliação e reflexão sobre a prática que permite a permanente revisão e adequação das atividades.

\section{Cooperação intersetorial}

Neste eixo as notas auto-atribuídas variaram entre 2 e 4 . Para as Unidades 2 e 3, a nota 2 reflete uma tendência de retração no trabalho intersetorial: "Já houve mais contato com as escolas. (...) Também com o Conselho Tutelar e o Centro Municipal de Atendimento Social Integrado já houve uma relação mais intensa do que a atual" (Unidade 3).

Isto pode ser entendido como conseqüência da dificuldade em estabilizar o trabalho na rotina da unidade, o que acaba consumindo o tempo da equipe nas atividades internas, não permitindo que se busquem parcerias que possam potencializar os esforços.

Na Unidade 1, a inexistência de uma equipe vinculada ao programa fez com que a assistente social buscasse apoio de grupos organizados da comunidade para viabilizar ao menos algum trabalho educativo.

“O grupo (...) tem participação nos trabalhos educativos realizados na unidade. O grupo (...) faz 


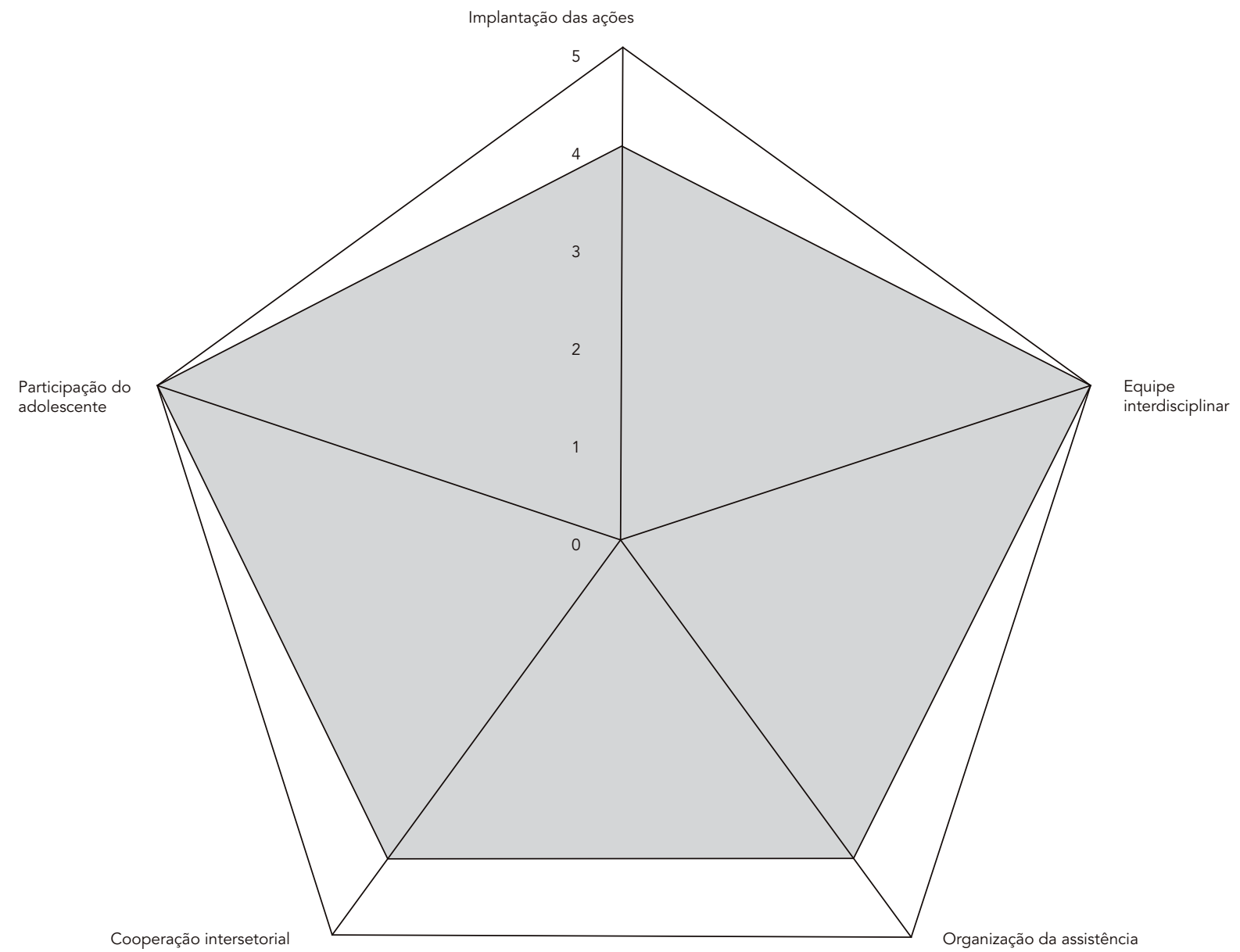

palestras para as meninas. Os dois grupos são da comunidade...".

A atuação do Adolescentro é essencialmente intersetorial e de parcerias.

“As parcerias são muitas e diversificadas. Em igrejas, escolas e creches fazem-se atividades educativas e captação durante a semana (...) Falta apoio para provisão de bolsas alimentação (mesmo para os participantes) e encaminhamentos para profissionalização e mercado de trabalho" (Adolescentro).

Entretanto, o grupo ainda sente falta de suportes para o desdobramento ("porta de saída") do trabalho que realiza , principalmente no âmbito da formação profissional e inserção dos jovens no mercado de trabalho.

\section{Participação do adolescente}

Neste eixo as notas auto-atribuídas variaram entre 3 a 5 . A questão da participação depende não apenas da receptividade dos serviços, mas, fundamentalmente, da capacidade do adolescente de expressar e defender seus interesses. A baixa politização da população, e deste grupo em especial, faz com que a participação se torne um objetivo a ser alcançado nos programas sociais, através de estratégias que visem o empoderamento e o reforço da cidadania.

"O projeto contribuiu para melhorar a acolhida ao adolescente, aumentando sua participação. Ainda falta melhorar a integração com trabalhos extra-muros" (Unidade 2). 
A baixa pontuação dada pelas unidades de saúde reflete a insatisfação ou mesmo frustração das equipes que gostariam de ser mais cobradas pelo seu público. Na Unidade 1, apesar da grande fraqueza do programa, a nota 3 deveu-se ao fato de que as poucas atividades educativas oferecidas só foram possíveis devido à parceria com grupos organizados de jovens locais: "A atividade educativa é apoiada por grupos da comunidade" (Unidade 1).

No caso do Adolescentro, a nota 5 reflete tanto a estrutura calcada no trabalho de promotores e monitores recrutados entre os jovens locais quanto as estratégias e organização das ações voltadas para o estímulo ao protagonismo dos jovens: "O trabalho tem se desdobrado com a formação de grupos autônomos” (Adolescentro).

\section{Discussão}

A gestão da mudança é um tópico que tem sido insistentemente estudado e discutido no campo do planejamento estratégico. Buscando explicar a resistência à mudança, O'Toole 23 formula hipóteses das quais destacaremos aquelas que melhor se aplicam ao caso estudado:

- Inércia: conceito emprestado da física que diz que o estado de movimento natural de um corpo só se altera quando uma força diferente de zero é aplicada sobre ele;

- Homeostase: conceito emprestado da biologia, significa que um organismo tende a reagir às alterações acionando mecanismos disponíveis para o restabelecimento do equilíbrio original;

- Medo: as pessoas temem o novo ou tendem a ser proteger do risco do desconhecido;

- Falta de conhecimento e/ou de meios: mesmo quando sensibilizados para mudança é preciso saber como promovê-la;

- Rebeldia: a mudança parece boa, mas tememos que conseqüências inesperadas possam nos ser prejudiciais;

- Genialidade individual vs. mediocridade do grupo: os "outros" não conseguem perceber a importância da mudança;

- Ideologia: temos visões de mundo diferentes e valores inerentemente conflitantes;

- Institucionalismo: os indivíduos mudam, mas as instituições não;

- Despotismo do hábito: as idéias da mudança são recebidas como críticas e reprovação ao grupo.

De uma forma ou de outra, em menor ou maior grau estes aspectos estão presentes nas unidades avaliadas. Tratando-se de serviço público existe uma tradição de centralização e verticalização que contribui muito mais para a acomodação do que para a flexibilização no nível local. A descentralização com pactuação de metas poderia contribuir para o rompimento da inércia e da homeostase, a exemplo do que pudemos observar com o Adolescentro. Sendo uma estrutura alternativa e flexível, diferente das unidades de saúde, consegue atuar como um agente catalisador das mudanças, contribuindo para transformar propostas novas em algo familiar, promovendo assim sua assimilação, mostrando "o que" e "como" mudar. Em contraposição a esta flexibilidade encontra-se o enrijecimento causado pela interdependência dos vários programas e ações desenvolvidos nas unidades. Nelas, qualquer mudança efetuada em um programa acarreta efeitos incontroláveis em outros, pois os recursos envolvidos são, praticamente, os mesmos. A intensificação de parcerias locais pode ser uma outra estratégia para a catalisação da mudança. Entretanto, é necessária uma verdadeira interação entre os parceiros e não uma simples delegação de atribuições, como acontece muitas vezes. A mudança tem que ser concebida como uma necessidade da equipe, pois o grupo tenderá a rejeitar tudo o que parecer "modismo efêmero”. Conseqüências inesperadas podem ser, por exemplo, "mais trabalho", "ter que desenvolver novas habilidades além das que já possuímos” e, para isto, é preciso haver motivação ou estímulo. A resistência institucional à mudança manifesta-se nas normas rígidas e pouco permeáveis a adaptações pontuais. Ação programática incorpora uma série de práticas de difícil contabilização e isto conflita, via de regra, com os conceitos de produtividade vigentes nos serviços.

Do ponto de vista da equipe, a eficácia da estratégia de mudança pressupõe a criação de uma aliança, envolvendo pessoas com alto grau de reconhecimento e legitimidade, expressa no consenso quanto à visão do futuro, assim como o compromisso e apoio a todo o grupo ao longo do processo 24 .

\section{Considerações finais}

As práticas de saúde passam por profundas modificações. A adoção do modelo das ações programáticas pressupõe a articulação entre a racionalidade clínica e a racionalidade epidemiológica promovendo uma organização da assistência baseada, ao mesmo tempo, na satisfação das necessidades dos usuários e na otimização dos recursos. A participação é um elemento chave, em especial no PROSAD, que tem, entre seus objetivos, o de estimular o protagonismo juvenil. Neste caso, participação precisa ser vista como um processo pedagógico que possibilite o de- 
senvolvimento de uma consciência crítica, um movimento no sentido de reverter relações de poder e afirmar a cidadania. Por outro lado, em um cenário de permanente transformação das necessidades, do conhecimento e dos recursos técnicos os conteúdos programáticos precisam ser constantemente atualizados e revistos, o que requer a participação em uma arena em que atores sociais negociam seus interesses distintos. A prática da avaliação vem crescendo nas instituições, embora não se configure, ainda, uma cultura da avaliação. Iniciativas criativas precisam

\section{Resumo}

Visando aumentar a adesão do homem jovem ao programa de atenção à saúde do adolescente, foi desenvolvido um projeto, implantado de forma piloto em cinco unidades básicas do Município do Rio de Janeiro, Brasil. Este artigo apresenta os resultados de uma avaliação conduzida ao fim do primeiro ano de implantação das ações do projeto, tendo como objetivo identificar características dos serviços que desempenham papel estratégico para mudança, assim com aqueles que contribuem para a resistência. A metodologia empregada baseia-se em técnicas de planejamento participativo e avaliação rápida (RAP). Considerando-se os princípios das práticas programáticas elaborou-se uma matriz com cinco eixos: implantação das ações do PROSAD, equipe interdisciplinar de saúde, organização da assistência, cooperação intersetorial e participação do usuário. Foram realizadas oficinas para auto-avaliação com as equipes locais. Observou-se que, apesar do bom nível de sensibilização dos profissionais, o resultado do projeto variou entre as unidades. Aspectos como a excessiva centralização e falta de flexibilidade parecem estar relacionados com a menor capacidade de incorporação de novas práticas. Por outro lado, nos serviços onde se adotaram estratégias específicas foram registrados resultados de sucesso.

Saúde do Adolescente; Saúde do Homem; Atuação Primária à Saúde ser incentivadas no sentido de contribuir para o maior engajamento e participação das equipes nos processos decisórios. A dinâmica da gestão requer dos serviços flexibilidade para promover ou incorporar mudanças. A resistência à mudança é natural e, portanto, toda proposta nova precisa ser introduzida por meio de uma estratégia que considere os aspectos positivos e negativos internos ao serviço e às condições externas que podem ser utilizadas favoravelmente ou para as quais se deve manter um alerta.

\section{Agradecimentos}

À Secretaria Municipal de Saúde do Rio de Janeiro, em especial à Viviane Manso Castelo Branco e ao Instituto Promundos. 


\section{Referências}

1. Organización Panamericana de la Salud. IMAN Servicios: normas de atención de salud sexual y reproductiva de adolescentes. Washington DC: Organización Panamericana de la Salud; 2005.

2. Ruzany MH, Andrade CLT, Esteves MAP, Pina MF, Szwarcwald CL. Avaliação das condições de atendimento do Programa de Saúde do Adolescente no Município do Rio de Janeiro. Cad Saúde Pública 2002; 18:639-49.

3. Ministério da Saúde. Portaria do Ministério da Saúde no. 980/GM. Cria o Programa de Atenção à Saúde do Adolescente. Diário Oficial da União 1989; $21 \mathrm{dez}$

4. Secretaria de Assistência à Saúde, Ministério da Saúde. Normas de atenção à saúde integral do adolescente. Brasília: Ministério da Saúde; 1993.

5. World Health Organization. Engaging men and boys in changing gender-based inequity in health: evidence from program interventions. Geneva: World Health Organization; 2007.

6. Contandriopoulos AP. Avaliando a institucionalização da avaliação. Ciênc Saúde Coletiva 2006; 11:705-11.

7. Novaes HMD. Avaliação de programas, serviços e tecnologias em saúde. Rev Saúde Pública 2000; 34:547-59.

8. World Bank. The World Bank participation sourcebook. Washington DC: Environmentally Sustainable Development, World Bank; 1996.

9. Secretaria de Assistência à Saúde, Ministério da Saúde. Saúde integral de adolescentes e jovens: orientações para a organização de serviços de saúde. Brasília: Ministério da Saúde; 2005.

10. Secretaria de Assistência à Saúde, Ministério da Saúde. Marco teórico e referencial: saúde sexual e saúde reprodutiva de adolescentes e jovens. Brasília: Ministério da Saúde; 2006.

11. Branco VMC. Os sentidos da saúde do adolescente para os profissionais [Dissertação de Mestrado]. Rio de Janeiro: Núcleo de Estudos de Saúde Coletiva, Universidade Federal do Rio de Janeiro; 2002.

12. World Health Organization. Adolescent friendly health services: an agenda for change. Geneva: World Health Organization; 2003.

13. Asmus CIRF, Raymundo CM, Barker SL, Pepe CCCA, Ruzany MH. Atenção integral à saúde de adolescentes em situação de trabalho: lições aprendidas. Ciênc Saúde Coletiva 2005; 10:953-60.
14. Denis JL, Champagne F.Análise da implantação. In: Hartz ZMA, organizadora. Avaliação em saúde: dos modelos conceituais à prática na análise da implantação de programas. Rio de Janeiro: Editora Fiocruz; 2000. p. 49-88.

15. Hartz ZMA. Avaliação dos programas de saúde: perspectivas teórico-metodológicas e políticas institucionais. Ciênc Saúde Coletiva 1999; 4: 341-53.

16. Bursztyn I, Branco VMC, Tura LFR. Avaliação do PROSAD: uma construção a partir dos atores. Saúde em Foco 2001; 21:97-114.

17. Bursztyn I, Ribeiro JM. Avaliação participativa em programas de saúde: uma proposta para o Programa de Atenção ao Adolescente. Cad Saúde Pública 2005; 21:404-16.

18. Scrimshaw S, Hurtado S. Rapid assessment procedures for nutrition and primary health care: anthropological approaches to improving program effectiveness. Los Angeles: UCLA Latin America; 1987.

19. World Health Organization. Improving urban health: guidelines for rapid appraisal to assess community health and needs. Geneva: World Health Organization; 1988.

20. Rifkin SB, Pridmore P. Partners in planning: information, participation and empowerment. Kuala Lumpur: MacMillian; 2001.

21. Macintyre K. The case for rapid assessment surveys for family planning program evaluation. In: Annual Meeting of the Population Association of America. http://www.cpc.unc.edu/pubs/paa_papers/1995/ macintyre.htm (acessado em 12/Mai/2003).

22. Nemes MIB. Prática programática em saúde. In: Schraiber LB, Nemes MIB, Mendes-Gonçalves $\mathrm{RB}$, organizadores. Saúde do adulto: programas e ações na unidade básica. São Paulo: Editora Hucitec; 1996. p. 48-65.

23. O'Toole J. Leading change: the argument for values-based leadership. New York: Ballantine Books; 1996.

24. Kotter, JP. Leading change. Boston: Harvard Business School Press; 1996.

Recebido em 06/Set/2007

Versão final reapresentada em 13/Fev/2008

Aprovado em 28/Mar/2008 